\title{
Transcarinal needle aspiration biopsy in the staging of lung cancer
}

\author{
J. Vansteenkiste*, L.M. Lacquet*, M. Demedts*, G. Deneffe*, E. Verbeken**
}

\begin{abstract}
Transcarinal needle aspiration biopsy in the staging of lung cancer. J. Vansteenkiste, L.M. Lacquet, M. Demedts, G. Deneffe, E. Verbeken. CERS Journals Ltd 1994.

ABSTRACT: Lung cancer without distant metastasis often requires an invasive surgical procedure to document inoperability. In order to determine how often puncture biopsy was a valid substitute for a surgical procedure, we investigated the performance of endoscopic staging by means of transcarinal needle aspiration biopsy during rigid bronchoscopy.

Eighty lung cancer patients with subcarinal lymph nodes visible on computed tomography (CT) scan were studied. Specimens were of histological quality (i.e. lymph node tissue) in 59 out of $80(74 \%)$ patients, and showed malignant invasion of this lymph node tissue in $\mathbf{4 3}$ cases. Specimens of cytological quality (i.e. lymph node cells) were obtained in 13 out of $80(16 \%)$ patients, and showed malignancy in 7 cases. Therefore, adequate evaluation of the subcarinal lymph nodes was possible in 72 out of $80(90 \%)$ patients. In 50 of these 72 , malignant mediastinal spread was proven, and further invasive surgical staging could be avoided. Subgroup analysis showed that this outcome tended to be more likely in patients with abnormal endoscopic appearance of the main carina, with locally extensive tumours, and with nonsquamous histology.

These results indicate that transbronchial needle aspiration biopsy of subcarinal lymph nodes can be a valuable alternative to more invasive surgical staging in patients selected by CT scan.
\end{abstract}

Eur Respir J., 1994, 7, 265-268. Depts of *Pneumology and **Pathology,
University Hospitals, Catholic University Leuven, Belgium.

Correspondence: J. Vansteenkiste Afdeling Longziekten

U.Z. Pellenberg

Weligerveld 1

B-3212 Pellenberg

Belgium

Keywords: Bronchoscopy

computer tomography scan

lung cancer

mediastinal staging

transcarinal

Received: May 131993

Accepted after revision October 1993
In the preoperative work-up of patients with lung cancer, evaluation of the mediastinum is of fundamental importance. The finding of enlarged lymph nodes on computed tomographic (CT) scan usually necessitates an invasive procedure in order to obtain tissue for histological examination. Indeed, malignant involvement of mediastinal subcarinal lymph nodes generally makes lung cancer patients poor candidates for surgical resection [1-3]. Less demanding procedures than surgery are, however, available.

Since the original paper by SChIEPPATI [4] in 1958, several authors have reported their experience with needle biopsies, using either rigid or flexible bronchoscopes. For this application we still prefer the rigid bronchoscope for several reasons. Firstly, in the preoperative assessment, we aim to minimize the risk of false positive results due to contamination of the specimen by endobronchial malignant cells. This risk - although low with the newer flexible devices - is still present in techniques using small diameter flexible needles [5-7]. Secondly, although our standard bronchoscopy is carried out by means of fibreoptics, expertise in rigid bronchoscopy has been maintained in our endoscopy unit, e.g. for laser photoresection and removal of foreign bodies. In good hands, the procedure is well-tolerated after mild to moderate i.v. premedication and under thorough topical anaesthesia. Thirdly, the price of single use transbronchial flexible needles prohibits its application in our country, since the cost of one needle is twice that of a bronchoscopy.

In this study, we investigated the performance of needle aspiration biopsy of subcarinal lymph nodes during rigid bronchoscopy. The selection of patients by chest CT findings of subcarinal lymph node enlargement was novel; and we are not aware of any other comparable large series report. The main purpose was to examine how often the puncture biopsy could be a substitute for the more invasive surgical exploratory procedures, without losing pathological accuracy. In addition, we have tried to identify the factors influencing diagnostic outcome.

\section{Methods}

Eighty patients (71 males), aged 43-78 yrs, with bronchogenic carcinoma and considered for surgery were studied between January, 1989 and December, 1992. All patients had a biopsy proven diagnosis of lung cancer, established by previous fibreoptic bronchoscopy. None 
had evidence of distant metastasis or unsuitability for surgery on medical grounds. Patients with obvious inoperability during previous fibreoptic bronchoscopy, e.g. carinal tumour or grossly abnormal carina, were also excluded.

Medical imaging of the mediastinum was performed by chest $\mathrm{CT}$ scan, with i.v. injection of contrast medium to locate mediastinal adenopathies. All patients had subcarinal lymphadenopathy of at least $10 \mathrm{~mm}$ diameter.

\section{Bronchoscopy and needle biopsy}

A rigid bronchoscope (Storz) was used, $43 \mathrm{~cm}$ long and of $8.5 \mathrm{~mm}$ bore. The 17-gauge rigid puncturing needle (Schiessle-needle) was $22 \mathrm{~mm}$ long and was connected to a $50 \mathrm{ml}$ syringe, filled with isotonic saline free of air bubbles. Medication consisted of topical lidocaine spray $10 \%$ and solution $2 \%$, atropine $0.50-0.75 \mathrm{mg}$ i.v., and pethidine 50-75 $\mathrm{mg}$ i.v. The main carina was inspected and considered abnormal if blunted or widened with bulging of the subcarinal bronchial wall. Cases with visible tumour in the carinal area were excluded. The carina was punctured bilaterally below its ridge, avoiding cartilage. Before suctioning, any piece of tissue that could have entered the needle during penetration of the bronchial wall was flushed by a drop of saline. The needle was then moved up and down in various directions in the lymphoid tissue, whilst an assistant applied continuous strong suction with the syringe. Finally, the needle was withdrawn, and the material within the needle or syringe flushed into a small container. The puncturing procedure was usually repeated four times, and up to six times in case of poor yield.

\section{Pathology}

All puncture material obtained was processed for histology and cytology. A pathologist examined all specimens, unaware of the clinical findings. Two specific questions were addressed: a) is the specimen of lymph node origin? This was answered positively if the specimen had histologic quality, or if there was a clear preponderance of lymphoid or malignant cells in the absence of bronchial cells; and b), is there malignancy in the specimen? In case of subsequent thoracotomy, the mediastinal nodes were sampled and labelled according to site of origin, so that the pathologies of both the puncture material and the surgical specimen could be accurately compared.

The position of the tumour was defined as "central" if visible through the fibreoptic brochoscope, and "peripheral" when not. Histology of the tumour referred to four cell types of the World Health Organization (WHO) classification [8]: squamous cell, adenocarcinoma, large cell and small cell carcinomas. Local extent of the tumour was scored according to T-category in the TNM-classification ( $\mathrm{T}$ (primary tumour), $\mathrm{N}$ (regional lymph node metastasis, $\mathrm{M}$ (remote metastasis)) [9].

\section{Data analysis}

Proportions were compared by means of a chi-squared distribution test with a significance level of $\mathrm{p}<0.05$.

\section{Results}

\section{Findings in the transcarinal aspiration biopsies (Fig. 1)}

Specimens were of histological quality in 59 out of 80 patients $(74 \%)$, and showed malignant node invasion in 43 of these cases. Specimens of cytological quality only were obtained in 13 patients (16\%), and 7 of these showed malignancy. Adequate mediastinal staging was thus possible in a total of 72 patients $(90 \%), 50$ of whom had a malignant and 22 a benign result.

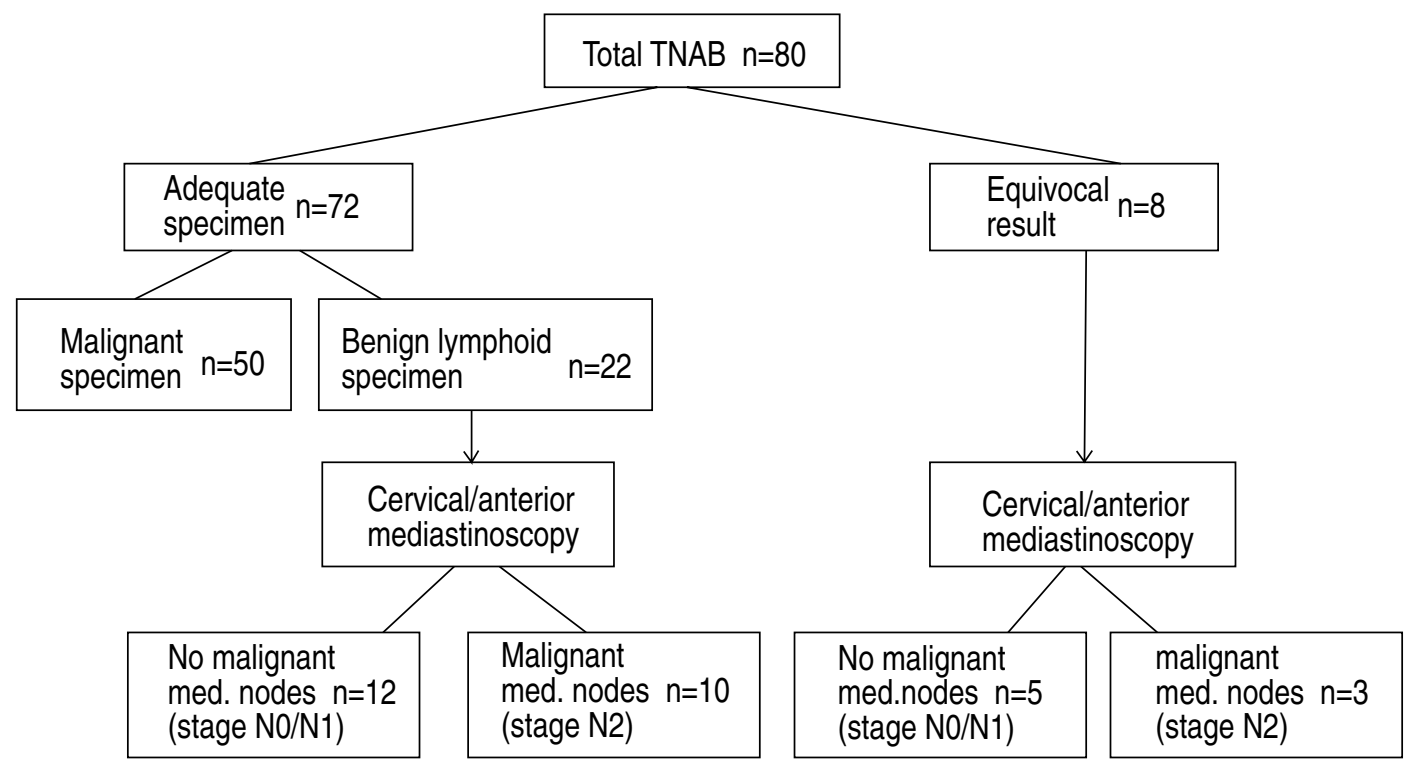

Fig. 1. - Flow sheet of patients. TNAB: transcarinal needle aspiration biopsy; med.: mediastinal 
The 50 patients having malignancy in their puncture specimen were not operated on. The 22 patients with benign lymphoid findings in the specimen were managed as follows: 12 patients, presenting a negative cervical or anterior mediastinoscopy, were operated on, and had tumour free subcarinal and other mediastinal lymph nodes (N0 or N1-disease). In 10 patients, malignant mediastinal nodes were found either in the superior paratracheal lymph nodes during cervical mediastinoscopy or in the para-aortic lymph nodes during left anterior mediastinoscopy (N2-disease). Of the eight patients with a doubtful result, five were without and three with N2 mediastinal nodes on mediastinoscopy.

\section{Influence of tumour characteristics on diagnostic yield}

The relationship between tumour characteristics and success rate of the procedure is given in Table 1. Good quality lymph nodes were obtained more often in patients with locally more extensive tumours, in central tumours, and in patients with abnormal endoscopic appearance of the carina. The difference was nearly significant for local extent of the tumour.

In the group of 72 patients with conclusive puncture results, we looked for factors associated with malignant invasion of the subcarinal nodes sampled (table 2). More malignant results were obtained in the patients with locally advanced T-category $(\mathrm{p}=0.02)$, and those with abnormal endoscopy of the carina $(\mathrm{p}=0.002)$. The chance of finding malignancy was also significantly higher in the group of patients with nonsquamous histology ( 37 out of 48) versus those with squamous cell tumour (13 out of 24 ) $(\mathrm{p}=0.04)$.

\section{Complications}

Complications were rare and mild: minor bleeding not requiring therapy after the procedure in one patient, transient fever with negative blood cultures in one patient, and a small pneumothorax not requiring aspiration in three others.

Table 1. - Tumour characteristics and biopsy quality

\begin{tabular}{lcccc}
\hline & Total & \multicolumn{2}{c}{ Good quality } & $\mathrm{p}^{*}$ \\
\hline $\begin{array}{l}\text { No. of patients } \\
\text { Tumour location }\end{array}$ & 80 & 72 & & \\
$\quad$ Peripheral & 32 & 27 & 84 & \\
$\quad$ Central & 48 & 45 & 94 & 0.17 \\
Tumour extent & & & & \\
$\quad$ T1-T2 & 45 & 38 & 84 & \\
$\quad 33-T 4$ & 35 & 34 & 97 & 0.06 \\
Cell type & 22 & 21 & 95 & \\
$\quad$ Large cell & 16 & 14 & 86 & \\
$\quad$ Adenocarcinoma & 28 & 24 & 86 & \\
$\quad$ Squamous cell & 14 & 13 & 93 & \\
$\quad$ Small cell & & & & \\
Endoscopic appearance of carina & & 46 & 87 & \\
$\quad$ Normal & 53 & 26 & 96 & 0.18 \\
$\quad$ Abnormal & 27 & & & \\
\hline
\end{tabular}

*: probability in Chi-squared distribution.
Table 2. - Chances of finding malignancy in subcarinal aspiration biopsy of good quality

\begin{tabular}{lcccc}
\hline & Total & $\begin{array}{c}\text { Malignant node } \\
\%\end{array}$ & $\mathrm{p}^{*}$ \\
\hline $\begin{array}{l}\text { No. of patients } \\
\text { Tumour location }\end{array}$ & 72 & 50 & & \\
$\quad$ Peripheral & 27 & 16 & 59 & \\
$\quad$ Central & 45 & 34 & 76 & 0.15 \\
Tumour extent & & & & \\
$\quad$ T1-T2 & 38 & 22 & 58 & \\
$\quad$ T3-T4 & 34 & 28 & 82 & 0.02 \\
Cell type & & & & \\
$\quad$ Large cell & 21 & 17 & 81 & \\
$\quad$ Adenocarcinoma & 14 & 10 & 71 & \\
$\quad$ Squamous cell & 24 & 13 & 54 & \\
$\quad$ Small cell & 13 & 10 & 77 & \\
Endoscopic appearance of carina & & & \\
$\quad$ Normal & 46 & 26 & 49 & \\
$\quad$ Abnormal & 26 & 24 & 89 & 0.002 \\
\hline
\end{tabular}

*: probability in Chi-squared distribution.

\section{Discussion}

The outcome of mediastinal lymph node evaluation often determines resectability of a lung cancer without distant metastases. Although patients with squamous cell carcinoma and limited mediastinal involvement are no longer considered definitely inoperable, they remain relatively poor candidates for surgery [1-3].

The primary aim of our study was to determine whether transcarinal aspiration biopsy through a rigid bronchoscope was a reliable substitute for surgical staging procedures in lung tumour patients with subcarinal lymph nodes visible on CT scan.

In our institute, about 200 lung cancer patients per year are candidates for surgery. Transcarinal aspiration biopsy, general anaesthesia and surgical procedures could be avoided in 50 out of the 80 patients in whom the puncture seemed justified during the 4 yrs of this study. This was especially valuable in elderly patients with impaired lung function, in whom the risk of a surgical procedure may be increased. Our results should be compared with those of other studies in which similar large diameter needles were used. WANG et al. [10] obtained a $73 \%$ diagnostic yield using a 18-gauge needle during rigid bronchoscopy. In a smaller series of 25 patients with either granulomatous or malignant disease, WANG [18] obtained 18 histology specimens with an 18-gauge needle through a large channel fibreoptic bronchoscope.

The procedure is also very attractive in patients who have a CT scan showing enlargement of the mediastinal lymph nodes in the subcarinal region only. These nodes - especially if located posteriorly - are poorly accessible via cervical mediastinoscopy, but are within easy reach of the rigid transcarinal needle. This was the case in 10 patients, and in all of them the specimens were of good quality and gave decisive results.

Using generally accepted pathological criteria (histological quality specimen, or good cytology with preponderance of lymphoid and malignant cells and absence of bronchial cells), our technique protects against false 
positive results caused by contamination with endobronchial malignant cells. The major concern with false positive results is that some patients would be denied a curative resection. A few false positives were described in most of the studies concerning punctures through flexible bronchoscopes [5-7]. Using that technique, SHURE and FEDUlLo [12] had no false positives, but obtained a sensitivity of only $15 \%$. Other studies of punctures through the flexible bronchoscope do not mention surgical control of the results $[11,13,14]$. The low but undeniable risk of false positive results and the lower yield with flexible bronchoscopic techniques prompted us to use the Schiessle-needle through a rigid bronchoscope. The procedure was well-tolerated and safe. Complications were few and minor, requiring no specific treatment. This is in agreement with the findings in other studies using large diameter biopsy needles $[10,11,14,15]$.

Relatively more node specimens of good quality were obtained in patients with advanced T-category. The specimens were more likely to be malignant in patients with advanced T-category, nonsquamous tumours, and abnormal main carina. The importance of an abnormal carina has been noted by others [12]. Nevertheless, we were able to obtain good quality specimens in $87 \%$, and to diagnose malignancy in $49 \%$, of the patients with a normal main carina. The higher frequency of malignancy in the nonsquamous group could be explained by the greater tendency for metastatic spread of adenocarcinomas and undifferentiated carcinomas.

\section{Conclusions}

In conclusion, transbronchial needle aspiration biopsy of the subcarinal nodes is a valuable alternative to more invasive surgical staging methods in patients selected by means of CT scan. The use of a large diameter Schiessleneedle through a rigid bronchoscope allows the application of quality criteria, precluding false positives. The procedure is more likely to have diagnostic outcome in patients with abnormal carina, and yet it was also conclusive in $87 \%$ of the patients with normal carina. Locally extensive or nonsquamous tumours more often yielded malignant tissue.

\section{References}

1. Pearson F, Delarue N, Ilves R, Todd T, Cooper J. Significance of positive superior mediastinal nodes identified at mediastinoscopy in patients with resectable lung cancer. J Thorac Cardiovasc Surg 1982; 83: 1-11.

2. Naruke T, Suemasu K, Ishikawa S. Surgical treatment for lung cancer with metastasis to mediastinal lymph nodes. J Thorac Cardiovasc Surg 1976; 71: 279-285.

3. Shields T. Surgical therapy for carcinoma of the lung. Clin Chest Med 1982; 3: 369-387.

4. Schieppati E. Mediastinal lymph nodes puncture through the tracheal carina. Surg Gynecol Obstet 1958; 110 : 243-246.

5. Harrow E, Oldenburg F, Lingenfelter M, Smith A. Transbronchial needle aspiration in clinical practice: a five year experience. Chest 1989; 96: 1268-1272.

6. Schenk D, Bower J, Bryan C, et al. Transbronchial needle aspiration staging of bronchogenic carcinoma. Am Rev Respir Dis 1986; 134: 146-148.

7. Cropp AJ, DiMarco AF, Lankerani M. False-positive transbroncial needle aspiration in bronchogenic carcinoma. Chest 1984; 85: 696-697.

8. Sobin L, Yesner R. Histologic typing of tumors. World Health Organization, Geneva, 1981.

9. Mountain C. Staging of lung cancer: the new international system. Lung Cancer 1987; 3: 4-11.

10. Wang K, Britt E, Haponik E, Fishman E, Siegelman S, Erozan Y. Rigid transbronchial needle aspiration biopsy for histological specimens. Ann Otol Laryngol 1985; 94: 382-385.

11. Wang K. Flexible transbronchial needle aspiration biopsy for histologic specimens. Chest 1985; 88: 860-863.

12. Shure D, Fedullo P. The role of transcarinal needle aspiration in the staging of bronchogenic carcinoma. Chest 1984; 86: 693-696.

13. Wang K, Terry P. Transbronchial needle aspiration in the diagnosis and staging of bronchogenic carcinoma. Am Rev Respir Dis 1983; 127: 344-347.

14. Mehta A, Kavuru M, Meeker D, Gephardt G, Nunez C. Transbronchial needle aspiration for histology specimens. Chest 1989; 96: 1228-1232.

15. Wang K, Marsh B, Summer W, Terry P, Erozan Y, Baker R. Transbronchial needle aspiration for diagnosis of lung cancer. Chest 1981, 80: 48-50. 